\title{
The impact of financial support on the success of small, medium and micro enterprises in the Eastern Cape province
}

\begin{tabular}{|c|c|}
\hline \multicolumn{2}{|c|}{$\begin{array}{l}\text { Authors: } \\
\text { Ellen C. Rungani }{ }^{1} \text { () } \\
\text { Marius Potgieter }{ }^{2}\end{array}$} \\
\hline \multicolumn{2}{|c|}{$\begin{array}{l}\text { Affiliations: } \\
{ }^{1} \text { Department of Business } \\
\text { Management, University of } \\
\text { Fort Hare, South Africa }\end{array}$} \\
\hline \multicolumn{2}{|c|}{$\begin{array}{l}{ }^{2} \text { Department of Business } \\
\text { Management, North-West } \\
\text { University, South Africa }\end{array}$} \\
\hline \multicolumn{2}{|c|}{$\begin{array}{l}\text { Corresponding author: } \\
\text { Ellen Rungani, } \\
\text { erungani@ufh.ac.za }\end{array}$} \\
\hline \multicolumn{2}{|c|}{$\begin{array}{l}\text { Dates: } \\
\text { Received: } 23 \text { Jan. } 2018 \\
\text { Accepted: } 15 \text { Apr. } 2018 \\
\text { Published: } 24 \text { July } 2018\end{array}$} \\
\hline \multicolumn{2}{|c|}{$\begin{array}{l}\text { How to cite this article: } \\
\text { Rungani, E.C., Potgieter, M., } \\
2018 \text {, 'The impact of financial } \\
\text { support on the success of } \\
\text { small, medium and micro } \\
\text { enterprises in the Eastern } \\
\text { Cape province', Acta } \\
\text { Commercii 18(1), a591. } \\
\text { https://doi.org/10.4102/ } \\
\text { ac.v18i1.591 }\end{array}$} \\
\hline \multicolumn{2}{|c|}{$\begin{array}{l}\text { Copyright: } \\
\text { (c) 2018. The Authors. } \\
\text { Licensee: AOSIS. This } \\
\text { is licensed under the } \\
\text { Creative Commons } \\
\text { Attribution License. }\end{array}$} \\
\hline \multicolumn{2}{|l|}{ Read online: } \\
\hline 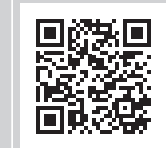 & $\begin{array}{l}\text { Scan this QR } \\
\text { code with your } \\
\text { smart phone or } \\
\text { mobile device } \\
\text { to read online. }\end{array}$ \\
\hline
\end{tabular}

Orientation: In developing economies, the growth of the economy could be fostered and enhanced by the expansion of the private sector, as this sector is the engine of economic growth. Consequently, it is necessary to accelerate the success of small, medium and micro enterprises (SMMEs) to achieve sustainability in this sector of the economy.

Research purpose: The main aim of this article was to determine the relevance of financial support offered to SMMEs by both private and public sectors on the success of businesses.

Motivation for the study: The impact of finance on SMME performance is well documented from an international perspective. However, what lacks in extant literature is the understanding of whether the financial support being offered by both public and private sectors is relevant to the success of businesses.

Research design, approach and method: A post-positivist paradigm was used with a quantitative research design, which made use of self-administered questionnaires to assess the relevance of financial support offered to SMMEs by both private and public sectors. Multiple regressions and correlations were computed to test the research hypotheses.

Main findings: The findings suggest that SMME success is positively and significantly correlated with financial support for both private and public sectors.

Practical/managerial implications: Although financial support is important, it needs to be restructured so as to incorporate practical aspects. Furthermore, private and public sectors should create an enabling environment that encourages the effective use of finances, which, in turn, will improve the success of businesses.

Contribution/value-add: This article is of particular value to policymakers for ways to improve the success of SMMEs.

\section{Introduction and background}

In developing economies, the growth of the economy could be fostered and enhanced by the expansion of the private sector, as this sector is the engine of economic growth. Consequently, it is necessary to accelerate the success of small, medium and micro enterprises (SMMEs) to achieve sustainability in this sector of the economy. The role of SMMEs is increasingly recognised all over the world in terms of their capacity for employment creation, social development and economic growth. Yet, the full potential of SMMEs remains untapped. According to the National Planning Commission (2011), SMMEs were identified as labour intensive and less capital intensive as little capital is needed for them to operate, and they often use local resources. Many SMMEs are unable to achieve their business goals by themselves. They need support and resources from both internal and external stakeholders, such as public and private institutions, and also from close associates who might be friends and relatives. Therefore, in a growing and developing economy like South Africa, channelling resources towards the SMME sector ultimately leads to a range of benefits for the entire South African population and economy.

In South Africa, a series of specific and suitable legislations has been introduced to support the stability and growth of SMMEs and to address some of the specific difficulties they face. This intervention is essential as research indicates that the rate of failure of SMMEs is specifically high within the first years of inception. More than $85 \%$ of SMMEs face significant survival challenges, and in the face of these challenges there is a need for a dynamic SMME sector development plan that would assign priority to the promotion of entrepreneurship and small 
business development for economic growth in developing economies (Ngwenya 2012; Nkonge 2013).

According to Statistics South Africa (Stats SA 2015), the SMME sector currently contributes approximately $42 \%$ of South Africa's gross domestic product (GDP) and accounts for $60 \%$ employment, as well as provides an incubator and breeding ground for entrepreneurship and innovation. Therefore, it is important to understand what contributes towards SMME success and link these contributions to enhance successful enterprises. The National Treasury (2015) indicates that job creation, wealth generation and improved standards of living for all South Africans are major issues that are capable of transforming the South African economy. However, Machirori and Fatoki (2013:115) point out that existing large firms and the public sector have been unable to solve major economic problems; hence, the importance of the SMME sector as a contributor to resolving the economic crisis should be acknowledged.

The number of SMMEs in South Africa has increased over the past seven years by only $3 \%$ from 2.18 million in the first quarter of 2008 to 2.25 million in the fourth quarter of 2015 as reported by Stats SA (2015). This growth is significantly less than the $14 \%$ growth expansion in GDP over the same period. Among the provinces, Limpopo has the highest growth rate in the number of newly registered SMMEs (34\%), followed by Gauteng (14\%). Even though the new SMME growth has declined in comparison to economic growth, SMMEs' contribution to GDP has increased, justifying the conclusion that SMMEs contribute to social development and economic growth in both developed and eveloping economies.

Given the important role of SMMEs in various economies, developing countries often take a favourable position towards SMME development. South Africa responded to the needs of SMMEs through the National Strategy and Promotion of Small Businesses in South Africa, as stipulated in the White Paper of 1995. According to this strategy, small businesses are to be developed as there is a need to create an enabling environment at both national and local levels. However, according to SME South Africa (2015), a major concern over the past decade has been the difficulty of transforming SMMEs into large firms, both regionally and globally.

According to the Global Entrepreneurship Monitor Report (GEM 2015), the top performing African economies with regard to entrepreneurship are Botswana and Senegal, with a total entrepreneurship activity (TEA) of 33\% and 38.6\%, respectively, and South Africa's TEA rate continues to lag behind at only $9.2 \%$. According to this report, a country at South Africa's level of economic development is expected to have a TEA rate in the range of $13 \%$. This, therefore, paints a bleak picture of the SMME sector's current potential to meaningfully contribute to economic growth, job creation and more equal income distribution in South Africa.
In spite of this encumbrance, there seems to be a growing optimism around entrepreneurship and the transformation of new SMMEs into established businesses.

In South Africa, the ability of SMMEs to create jobs is clearly a major attraction for both public- and private-sector investors. Therefore, there is a dire need for supporting SMMEs so that they can grow and flourish (Booyens 2011:67). One major challenge in business support interventions for SMMEs in South Africa is the lack of emphasis on the crucial areas that enhance the success rate and sustainability of SMMEs (Mashombo 2014:5; Pergelova \& Angulo-Ruiz 2014:663). Given the relative scarcity of the typical SMME achieving substantial growth, academics, management experts and government have been keen to discover ways in which SMME success could be encouraged (FinMark Trust 2010).

Evidence from the GEM (2015) suggests that access to formal financial support in South Africa is no worse than it is in other developing countries. Only $27 \%$ of people starting businesses expected to receive loans from formal financial institutions. While this suggests that most people starting businesses struggle to secure finance from formal financial institutions, the pattern in other developing countries included in the GEM is no different from South Africa (Fatoki 2012a; Mapfumo 2015; Mqaba 2015).

There are two primary sources of external finance for new SMMEs: equity and debt. External equity in the form of venture capital or the stock exchange is normally long term but is usually not available for new SMMEs, primarily because of relatively small levels of financing desired by a new SMME. The lack of external equity makes many new SMMEs dependent on bank loans and overdrafts, and supplier credit for early stage financing. Despite the dependence of SMMEs on debt, financial access is very limited for new SMMEs, especially in developing countries (Beck 2009; Chimucheka 2012).

The SMME financial market reveals that South Africa has a variety of funding programmes and financing schemes by both the public- and private-sector funding agencies. It was also noted that despite the availability of an array of funding programmes, the awareness of these programmes and the uptake have been very low (Department of Trade and Industry [DTI] 2015), especially for government-supported schemes. For those SMMEs that apply for finance, the rejection rate has been high, particularly for bank-sponsored schemes. There seems to be:

- General lack of awareness of funding programmes.

- A mismatch between the products offered on the supply side and that which is required by the SMME market.

- A gap between minimum requirements for a business loan and status (especially on the issue of formality) of the majority of SMMEs.

This means that even registered microenterprises are less likely to have access to credit. Furthermore, a large proportion 
of SMMEs are completely excluded from the financial market (Bosire \& Nzaramba 2014; Chiliya \& Roberts-Lombard 2012; Chimucheka 2012; Dumbu \& Chidamoyo 2012; Fatoki 2011; Kamange, Njeru \& Tirimba 2014; Krajcovicova 2012; Madya 2015; Sarakunze 2015).

Micro finance institutions (MFIs), on the other hand, have structures in place for smaller loans, but the loans are at high interest rates that the smallest businesses cannot afford. Other factors inhibiting SMMEs' access to credit include the lack of business managerial experience and skills, insufficient information on available products, relatively low levels of financial literacy, poor business plans and other external factors (Dumbu \& Chidamoyo 2012; Kamange et al. 2014; Madya 2015; Sarakunze 2015).

This literature review revealed that there are a number of sources of credit for SMMEs. However, it is not possible to determine with any degree of accuracy whether the financing available is sufficient to meet the needs of the SMME sector because of the lack of information, especially with regard to the demand side and the specific causes for the lack of access. Therefore, more research is needed in this area to identify (1) the specific requirements of the SMME sector when it comes to financing and (2) whether the financing available meets those requirements in terms of both 'quantity' and 'quality' (Bosire \& Nzaramba 2014; Fatoki 2011; Kamange et al. 2014; Sarakunze 2015; Tlhomola, Rankhumise \& Van Niekerk 2010).

Sarakunze (2015) indicates that there is a possibility that there is sufficient credit available, but the terms and conditions under which it can be accessed are not favourable for the SMME sector that it is intended to serve. In this case, the policy response should not be designed to increase the amount of credit available to the sector but revisit the product offering of the credit already available and ensure that it meets the needs of the SMME sector that it is intended to serve.

Another possibility is that the credit available ought to be sufficient to meet demand, but the lack of access is attributed either to the specific characteristics of the SMMEs applying for the loan or the lack of awareness that the financing is available. In these instances, the policy response required would necessarily be different from that of increasing funding available or, indeed, changing product design offering (Chimucheka 2016; Mapfumo 2015; Mqaba 2015).

Given that an alarming percentage of SMMEs are unsuccessful, it is relevant to investigate the causes of poor performance and failure faced by SMMEs. According to Gray, Saunders and Goregaokar (2012:573), the failure of SMME is an important area of research, and they rightly state that no policy can be formulated for SMME without an in-depth understanding of how the business malfunctions. This comprises the identification of major problems that impede SMME performance. Numerous research studies have been conducted on the success and growth factors of new firms (Fatoki 2012:179). In contrast, little has been done to examine factors contributing towards the poor performance and failure of established SMMEs in developing economies. Against this background, the objective of this study was to determine the relevance of SMME finance on the success of SMMEs.

\section{Research problem}

Fostering small enterprises into medium enterprises with the key objective of improving job creation in South Africa has become a top priority for both public and private sectors. However, a key challenge lies in the business skills required to grow the small enterprises through various stages of business transformation (Lampadarios 2015:32).

According to the DTI (2015), five out of seven SMMEs in South Africa fail within 1 year of operation. In addressing the problem of the unsatisfactory success rate of SMMEs, public and private sectors crafted numerous SMME development support programmes, with some being paid for and some are provided for free to SMMEs. One of the typical challenges in business management research is the contribution of both public and private sectors to SMMEs' success and development. Therefore, there is a need to scrutinise the impact and relevance of public- and privatesector financial support for SMMEs in South Africa. The disturbing situation of the high failure rate of SMMEs as highlighted in the GEM (2015) also indicated that this situation could possibly be minimised through the right type of intervention at the right time by relevant stakeholders. One of the greatest difficulties confronting policymakers is how best to develop an approach for SMMEs that could achieve a sufficient degree of coordination between the supply effort and demand potential. Hence, the research problem of this study focuses on identifying the financial support intervention required to reduce the failure rate of SMMEs in South Africa.

\section{Research question}

To assist in answering the research problem, this section discusses the research questions emanating from the research problem addressed by this study.

What type of support is needed for the sustainable development of small, medium and micro enterprises in South Africa?

Small, medium and micro enterprises are established to foster the economic growth and development of an economy. However, the fact that too many of these businesses are unsuccessful should be seriously considered because of the adverse effect they have on the economy in the short and long run (Lampadarios 2015:32; Nkonge 2013:194). The support and promotion of SMMEs over the years has become a major priority in South Africa. However, one major challenge in business support interventions for SMMEs in South Africa is a lack of emphasis on the contingencies that improve the success and sustainability of 
SMMEs in South Africa (Mashombo 2014:5; Pergelova \& Angulo-Ruiz 2014:663).

Therefore, it is imperative to define support that is needed to improve the SMME success rate and thus bolster the effectiveness of public- and private-sector business support interventions. In particular, there is a need to take a closer look at the application of the business management model for the provision and development of SMME support programmes by both the government and the private sector.

\section{Research sub-questions}

To answer the main research question of this study, the following are the sub-research questions addressed by this study.

How relevant is the financial support provided by both the private and public sectors to the success of SMMEs in South Africa?

The quality of support provided to SMMEs by both the public and private sectors is very important for the success of SMMEs. Therefore, there is a need to evaluate the manner in which business support interventions function, as perceived by SMMEs, and the relevance of these support interventions to the success of SMMEs using a demand-side approach.

This study determines if there is a mismatch between the supply and demand of SMME business support interventions. There is a need to evaluate the relevance of the available support that SMMEs receive in comparison to the success rate of SMME businesses.

Are SMMEs receiving applicable support with respect to the right functional areas of business, for the proper duration, at the correct stage of the business life cycle and by the relevant people?

One of the greatest difficulties confronting policymakers is how best to develop an approach for SMMEs which could achieve a sufficient degree of coordination between supply effort and demand potential. There is thus a need to evaluate the available functional support SMMEs receive compared to what they actually need to improve the success of their businesses. Thus, this study formulates a framework that could be used to gauge the support needed to improve the success rate of SMMEs in South Africa to the benefit of policymakers, researchers, academia and ultimately the business community in South Africa.

\section{Objectives of the study}

To create a clear link between the research problem and research questions, this section deals with the research objectives pertinent to this study. The main objective of this study is to:

- Examine the effect of financial support (from both public and private institutions) on the overall success of SMMEs.

- Determine the impact of financial support from both public and private sectors on the success of SMMEs.
- Establish and ascertain how SMMEs in South Africa perceive the relevance of business interventions (from both private and public sectors) for business success.

- Assess if there exists a gap between SMME expectations and the support provided by both private and public sectors.

\section{Hypotheses of the study}

This study used hypotheses to state specific relationships between variables in such a way that the relationships can be empirically tested. Furthermore, the hypotheses were used to validate the theories used in the research and to allow logical analysis of relationships of variables so as to deduce the interplay of those variables other than those stated in theory.

The following are the hypotheses of this study:

$\mathbf{H}_{01 \mathrm{a}}$ : There is no significant relationship between financial support given by the public sector and SMME success.

$\mathrm{H}_{1 \mathrm{a}}$ : There is a significant relationship between financial support given by the public sector and SMME success.

$\mathbf{H}_{01 \mathrm{~b}}$ : There is no significant relationship between financial support given by the private sector and SMME success.

$\mathbf{H}_{1 \mathrm{~b}}$ : There is a significant relationship between financial support given by the private sector and SMME success.

$\mathbf{H}_{03 \mathbf{a}}$ : There is no concurrence in business interventions delivered by the public sector and SMME needs.

$\mathbf{H}_{3 \mathbf{a}}$ : There is a concurrence in business interventions delivered by the public sector and SMME needs.

$\mathbf{H}_{03 \mathbf{b}}$ : There is no concurrence in business interventions delivered by the private sector and SMME needs.

$\mathbf{H}_{3 \mathrm{~b}}$ : There is a concurrence in business interventions delivered by the private sector institutions and SMME needs.

$\mathbf{H}_{04}$ : There is a gap between SMME expectations and the support provided by both private and public sectors.

$\mathbf{H}_{4}$ : There is no gap between SMME expectations and the support provided by both private and public sectors.

\section{Theoretical background}

A theoretical background is provided to formulate the structure that holds the theory of a research study. This section provides the theoretical framework that explains why the research problem under study exists. The following discussion provides the theoretical background of this study.

\section{Resource-based theory}

The resource-based theory (RBT) suggests that business resources and capabilities influence the growth and performance of a business. This theory emphasises the importance of resources and the capabilities of a business (Davis \& Cobb 2010:21) as illustrated in Figure 1.

For sustainable competitiveness, businesses should have their own resources and capabilities that cannot be imitated by other businesses. This business-specific ability is important, as is the technological and managerial environment. 


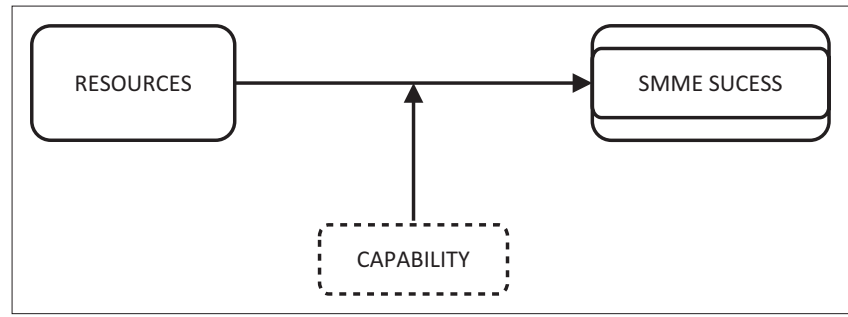

Source: Geoffrey, J. \& Christos, P., 2015, 'Entrepreneurial imagination and a demand and supply-side perspective on the MNE and cross-border organization', Journal of International Management 21, p. 321. https://doi.org/10.1016/j.intman.2015.07.003

FIGURE 1: Resource-based theory.

Resources include financial assets, manufacturing equipment, brand name, technological knowledge, marketing know-how and management skills. Capabilities refer to special abilities of efficiently managing, utilising and increasing businessspecific resources. The more business-specific resources and capabilities a business professes to hold, the more valuable the business is compared to competitors. Therefore, businesses that have competitive resources could enter a new market easily. Using these resources and capabilities, businesses have advantages in entering the market and gaining more profit (Geoffrey \& Christos 2015:321).

The RBT provides a background to explain how businesses could identify appropriate measures to overcome growth impediments and have improved access to technology resources, infrastructure, workforce resources, financial resources, and access to the market. Thus, SMMEs have to develop and maintain long-term relationships with their suppliers and customers in order to achieve the required resources that are critical for their survival and success. However, in spite of these criticisms, the effect of the RBT on strategic management research has been vital. This is mainly because the RBT has moved emphasis in the strategy literature away from external factors (such as industry position) towards internal business resources as sources of competitive advantage. Rising acceptance of internal resources as sources of competitive advantage has brought acceptability to the affirmation that people are strategically significant to business success.

Although the RBT emerged from management studies based on corporate management and large multinational organisations, some scholars and researchers (Chimucheka 2012; Collett, Pandit \& Saarikko 2014; Gumbo 2015; Kamange et al. 2014:12; Kim 2011; Krajcovicova 2012; Sarakunze 2015) used the theoretical conclusions of these concepts in terms of management issues in small and medium-sized enterprises in the context of growth and innovation implementation processes.

The RBT is appropriate as a theory that supports business performance for a number of reasons. Firstly, there is a human capital pool encompassing the stock of employee understanding, skills, motivation and behaviours. Human resources (HR) practices contribute towards and can help build the knowledge and skill base, as well as elicit relevant behaviours. Secondly, there is the flow of human capital

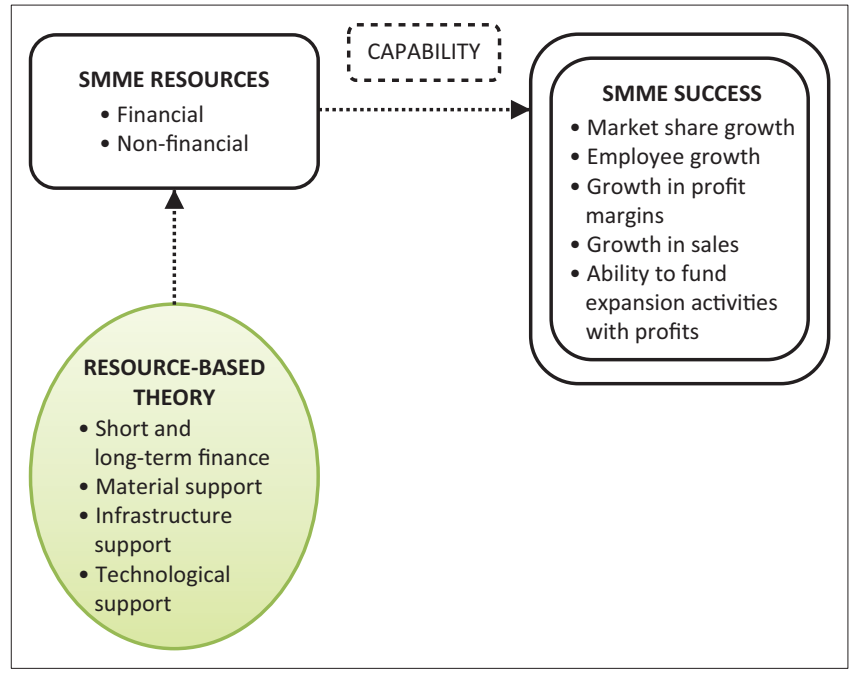

Source: Geoffrey, J. \& Christos, P., 2015, 'Entrepreneurial imagination and a demand and supply-side perspective on the MNE and cross-border organization', Journal of International Management 21, p. 321. https://doi.org/10.1016/j.intman.2015.07.003

FIGURE 2: Theoretical framework of the study.

through the business. This mirrors the movement of people (with their individual knowledge, skills and abilities), as well as knowledge itself. Human resources practices can certainly influence the movement of people. However, more importantly, the types of incentive systems, culture and other aspects of HR management influence the extent to which employees are willing to create, share and apply knowledge internally. Thirdly, the vibrant processes by which businesses change and/or renew themselves constitute the third area illustrating the link between $\mathrm{HR}$ management and the resource-based view of an organisation. Human resources practices are the primary levers through which an organisation can vary the pool of human capital as well as attempt to change employee behaviour which all contributes towards business success.

Based on the above arguments, RBT supports the associations described in this study as shown in Figure 2.

\section{Research methodology}

The ontological assumption that was taken for this study is the objectivity perspective of viewing reality. It is assumed that reality exists independently of its comprehension and it is possible to establish and explain universal principles and facts through robust and replicable methods (Bryman et al. 2014). Therefore, objectivity and neutrality are observed as far as possible in the interpretation and presentation of this research.

The post-positivist approach is followed because of the nature of this study. The research focuses on factors and causality and fundamental laws which call for a postpositivist approach. Furthermore, because the study has hypotheses that need to be tested, the post-positivist approach is the most suitable. In this study, the researcher remains independent from the phenomena that are researched. Post-positivism often involves the use of existing theory to develop hypotheses that are then tested during the 
research process. In this study, theory was elaborated and hypotheses were devised. The mixed-method approach was regarded as suitable for this study because the phenomenon studied was defined and data were gathered and evaluated according to prescribed rules that can be reviewed for error and measured by validity and reliability. The mixed research paradigm mixes quantitative and qualitative methods or paradigm characteristics (Bryman et al. 2014; Maree \& Pietersen 2014; Quinlan 2011:382; Zikmund \& Babin 2010).

\section{Information types and sources}

There are two types of data that researchers use when conducting a research: primary and secondary data (Maree \& Pietersen 2014). Both types of data were used for this study.

\section{Primary data}

Primary data were collected directly from a research population through fieldwork. For the purpose of this study, primary information was obtained through a survey and a self-administered questionnaire.

\section{Secondary data}

The sources of secondary data that were utilised for obtaining information required for this study are contained in published and electronic forms such as:

- academic books

- research journals

- databases and electronic theses.

\section{Population}

This section discusses the target population of this study as well as the population frame and criteria.

\section{Research population}

This research seeks to establish the relevance and effectiveness of business support intervention for SMMEs from the demand side by looking at the support provided to SMMEs by the public and private sectors. The population for this study are formal SMMEs in the Eastern Cape Province of South Africa. The Eastern Cape was chosen because it is one of the provinces with low levels of SMME growth (Stats SA 2015). Also, the province has two metropolitan municipalities and six district municipalities that host both urban and rural SMMEs. The Eastern Cape Development Corporation (ECDC) indicated that there are 350 formal active and registered SMMEs conducting business activities under its jurisdiction. This study is limited to this population frame because it only looks at the formal sector.

\section{Population frame}

The population list provided by ECDC served as the sample frame for this study. The sample frame consisted of registered SMMEs in the formal sector of the Eastern Cape.

\section{Population size}

The research frame contains the names and contact details of 350 SMMEs registered with ECDC. A census was undertaken and because of the number of SMMEs formerly registered, this enabled:

- A true measure of the population (no sampling error).

- Benchmark data may be obtained for future studies.

- Detailed information about small sub-groups within the population is available.

\section{Accessibility of respondents}

The researcher liaised with different municipalities and the local Chamber of Commerce dealing with SMMEs to obtain access to SMME representatives who acted as respondents during training and business expos.

\section{Research instrument}

Because of the objective ontology and a post-positivist epistemology, the mixed-method approach was deemed suitable for this study. In this case, the research approach commenced with a theoretical background to the research topic and then derived testable hypotheses from it. A mixedmethod research was utilised in this research and, in particular, the study used a concurrent embedded mixed method where emphasis is placed on quantitative data with very limited use of qualitative data. The primary purpose was to collect quantitative data to test the research theories that predict that independent variables are influenced by dependent variables. A secondary purpose was to gather qualitative data through open-ended questions to explore the central phenomenon of the study. The reason for collecting qualitative data was to address different questions and provide for triangulation of data sources and findings. A survey method was used to collect data and participants answered questions administered through self-completed questionnaires. After the participants answered the questions, these responses were described. For the survey to be both reliable and valid, the questions were constructed using tried-and-tested measurement scales. This research study can be replicated or repeated, given its high reliability. A questionnaire survey was used to collect data from respondents. A structured format was used and the same questions in the same order were asked to different respondents to create a database of answers for analysis. A survey allows the exploitation of the natural variation in variables and establishes associations. The measurement scales used in the questionnaire were adopted from triedand-tested instruments after an extensive literature review. Only measurement scales with a Cronbach's alpha of more than 0.70 were adopted.

\section{Data analysis}

Data analysis was performed with the help of a statistician. In addition, the Statistical Package for Social Sciences (SPSS) version 24.0 for Windows was used for data analysis. To summarise and describe data, the researcher used descriptive 
statistics. Pearson's correlation test was used to test the strength and skewness of the relationship between variables in accordance with the objectives of this study. Inferential statistics to test the hypotheses were in the form of tests from means, notably the $t$-test (to compare means of variables) and the analysis of variance (ANOVA) test to compare variation within and between two or more variables. In addition, regression analysis (simple and multiple) was employed to obtain the prediction power of explanatory variables on the dependent variables.

Small, medium and micro enterprises' success is measured by profitability, growth in employees, increase in sales and period of operation and is expressed through the following equation:

Success $_{i}=\alpha_{0}+\beta_{n} X_{n, i}+\varepsilon_{i}$

$\alpha_{0}$ is the value of success if all explanatory variables have a value of $0 . \beta_{n}$ represents the coefficients of interest. Statistical significance is observed from the $p$-value of each of the $\beta$ values. $X$ is a vector of explanatory variables used in the model, from 1 up to the $n$th variable. If simple regression is tested, $n=1$. $\varepsilon$ is the error term capturing all unobservable characteristics of the SMMEs. $i$ is a subscript that represents the $i$ th SMME.

\section{Ethical considerations}

All ethical standards for this research were observed, and confidentiality was maintained by keeping the data confidential and not revealing respondents' identities when reporting or publishing the study. The respondents were informed about the purpose of the study and the procedures that would be used to collect the data. Written ethical clearance was obtained from the North-West University and the ECDC and the Human Sciences Research Ethics Committee (HSREC) of the university (REF: NWU-0047316-A9). Permission was also obtained from all participating SMME owners and/or managers. Consent from respondents was also obtained before they participated in the survey.

\section{Validity and reliability}

Internal validity was sought through an extensive literature review as well as piloting the questionnaire. To ensure face, criterion-related, content and construct validity, the researcher utilised a statistician and experts to assess the research instrument for theoretical and conceptual clarity as well as pre-testing the research instrument in a pilot study. In addition, all assumptions were clearly stated in order for other researchers to identify underlying assumptions following similar research. Reliability was tested using the Cronbach's alpha test (Table 1).

\section{Limitations of the study}

There are limitations in the scope and method of any study. This study concentrated on both the public- and private-
TABLE 1: Reliability of scales.

\begin{tabular}{lccc}
\hline Scale & Question & Items & Cronbach's alpha \\
\hline $\begin{array}{l}\text { Small, medium and micro enterprise } \\
\text { success }\end{array}$ & 6 & 8 & 0.815 \\
Financial support & 10 & 7 & 0.662 \\
The impact of private-sector support & 14 & 5 & 0.654 \\
The impact of public-sector support & 14 & 5 & 0.654 \\
Relevance of public-sector support & 13 & 7 & 0.619 \\
Relevance of private-sector support & 13 & 7 & 0.619 \\
Relevance of public-sector support & 15 & 7 & 0.682 \\
Relevance of private-sector support & 15 & 7 & 0.680 \\
$\begin{array}{l}\text { Monitoring and evaluation of small, } \\
\text { medium and micro enterprise success }\end{array}$ & 16 & 4 & 0.873 \\
\hline
\end{tabular}

sector sources of support for a closer look at the perception of beneficiaries (SMMEs) but does not incorporate the views of service providers because of time, geographical and financial constraints.

The reliability scores of the scales used in the research instrument suggest that all scales were reliable. Scales that had lower Cronbach's alpha values were those scales that were custom-developed for this study, for example the scale used to measure if SMMEs plough back into the SMME sector. This is a new scale developed specifically for the purpose of this study, which explains the lower level of the Cronbach's alpha score. However, in general, all the scales were above 0.65 , which shows that the items used to measure the research constructs for this study were reliable.

\section{Hypothesis 1: Testing for private sector financial support}

$\mathbf{H}_{01 \mathbf{a}}$ : There is no significant relationship between financial support given by the private sector and SMME success.

$\mathbf{H}_{1 \mathrm{a}}$ : There is a significant relationship between financial support given by the private sector and SMME success.

To test this hypothesis, correlation and multiple regression analyses were performed and the results obtained are presented in Tables 2 and 3.

The results of the correlation analyses conducted to establish if there is a significant relationship between the predictors of financial support given by the private sector and SMME success shown in Table 2 suggest that SMME success is significantly positively correlated with raw materials grants $(p=0.658)$, start-up grants $(p=0.711)$ and marketing support grants $(p=0.646)$ as predictors of financial support given by the private sector. This indicates that these forms of financial support contribute largely to the success of SMMEs. Infrastructure grants $(p=-0.58)$ and technology grants $(p=-0.846)$ are non-significantly negatively correlated, indicating that these forms of support do not contribute largely to SMME success.

The results from the multiple regression model (Table 3) with the five predictors (two predictors - provision of secured funding and provision of non-secured funding were removed because of collinearity) produced $R^{2}=0.423$, $F_{\text {dist }}=1.556, p=0.012$ (which is $<0.05$ ). The value of $R$-squared 
TABLE 2: Correlations: Hypothesis $\left(\mathrm{H}_{0 \mathrm{a}}\right)$.

\begin{tabular}{|c|c|c|c|c|c|c|}
\hline \multirow[t]{2}{*}{ Model } & \multicolumn{2}{|c|}{ Unstandardised coefficients } & \multirow[t]{2}{*}{$t$} & \multirow{2}{*}{$\begin{array}{l}\text { Correlation with } \\
\text { SMME success }\end{array}$} & \multicolumn{2}{|c|}{$95.0 \%$ Confidence interval for B } \\
\hline & B & Std. error & & & Lower bound & Upper bound \\
\hline (Constant) & $2.249 * * *$ & 0.407 & 5.521 & - & 1.448 & 3.050 \\
\hline Raw material grants & $-1.347^{*}$ & 0.573 & -0.607 & $0.658 *$ & -1.474 & 0.779 \\
\hline Infrastructure grants & 2.093 & 0.576 & 0.161 & -0.578 & -1.041 & 1.227 \\
\hline Start-up grants & $1.093^{*}$ & 0.546 & 0.161 & $0.711^{*}$ & -1.041 & 1.227 \\
\hline Technology grants & $-2.180 *$ & 0.781 & -2.208 & -0.846 & -0.340 & -0.020 \\
\hline Marketing support grants & $1.024 *$ & 0.481 & 0.293 & $0.646 * *$ & -0.184 & 0.136 \\
\hline
\end{tabular}

SMME, small, medium and micro enterprise.

$*, p<0.05 ; * *, p<0.01 ; * * *, p<0.001$.

TABLE 3: Multiple regression hypothesis $\left(\mathrm{H}_{012}\right)$.

\begin{tabular}{|c|c|c|c|c|c|c|c|c|}
\hline Model & Sum of squares & Df & Mean square & $F$ & Sig. & $R$ & $R$ square & $\begin{array}{l}\text { Standard error of } \\
\text { the estimate }\end{array}$ \\
\hline Regression & 3.676 & 5 & 0.735 & 1.556 & 0.012 & 0.651 & 0.423 & 0.687 \\
\hline Residual & 156.833 & 332 & 0.472 & - & - & - & - & - \\
\hline Total & 160.509 & 337 & - & - & - & - & - & - \\
\hline
\end{tabular}

$\mathrm{Df}$, these are the degrees of freedom associated with the sources of variance; $F$, the F-statistic is the Mean Square; sig, the $p$-value; $R$, is the square root of $R$-squared and is the correlation between the observed and predicted values of dependent variable; $R$-squared, this is the proportion of variance in the dependent variable.

TABLE 4: Correlations: Hypothesis $\left(\mathrm{H} 1_{\mathrm{ob}}\right)$.

\begin{tabular}{|c|c|c|c|c|c|c|}
\hline \multirow[t]{2}{*}{ Model } & \multicolumn{2}{|c|}{ Unstandardised coefficients } & \multirow[t]{2}{*}{$t$} & \multirow{2}{*}{$\begin{array}{l}\text { Correlation with } \\
\text { SMME success }\end{array}$} & \multicolumn{2}{|c|}{$95.0 \%$ Confidence interval for B } \\
\hline & B & Std. error & & & Lower bound & Upper bound \\
\hline (Constant) & $2.242 * *$ & 0.416 & 5.394 & - & 1.424 & 3.059 \\
\hline Raw material grants & $-0.167 *$ & 0.077 & -2.166 & $-0.546 *$ & -0.318 & -0.015 \\
\hline Infrastructure grants & -0.021 & 0.130 & -0.163 & $-0.641 *$ & -0.278 & 0.235 \\
\hline Start-up grants & -0.184 & 0.190 & -0.968 & $0.766 *$ & -0.558 & 0.190 \\
\hline Technology grants & -0.105 & 0.076 & -1.381 & -0.546 & -0.255 & 0.045 \\
\hline Marketing support grants & 0.120 & 0.131 & 0.914 & $-0.646 *$ & -0.138 & 0.378 \\
\hline
\end{tabular}

SMME, small, medium and micro enterprise.

$B$, the values for predicting the dependent variable from the independent variable; $t$, t-statistics.

$*, p<0.05 ; * *, p<0.001$.

TABLE 5: Multiple regression model: Hypothesis $\left(\mathrm{H}_{01 \mathrm{~b}}\right)$.

\begin{tabular}{|c|c|c|c|c|c|c|c|c|}
\hline Model & Sum of squares & Df & Mean square & $F$ & Sig. & $R$ & $R$ square & $\begin{array}{l}\text { Standard error of } \\
\text { the estimate }\end{array}$ \\
\hline Regression & 5.284 & 5 & 1.057 & 2.260 & 0.048 & -0.481 & 0.231 & 0.684 \\
\hline Residual & 155.225 & 332 & 0.468 & - & - & - & - & - \\
\hline Total & 160.509 & 337 & - & - & - & - & - & - \\
\hline
\end{tabular}

$\mathrm{Df}$, these are the degrees of freedom associated with the sources of variance; $F$, the F-statistic is the Mean Square; sig, the $p$-value; $R$, is the square root of $R$-squared and is the correlation between the observed and predicted values of dependent variable; $R$-squared, this is the proportion of variance in the dependent variable.

indicates that $42.3 \%$ variation of SMME success can be explained by the financial support predictors. However, the results from the coefficients of the multiple regression model indicate that a unit increase in SMME success corresponds to a -1.35 significant decrease in raw material financial support grants, 1.09 significant increase in start-up grants, -2.18 significant decrease in the technology grants and -1.02 significant increase in marketing support grant weight. Therefore, the null hypothesis could not be accepted as $p=0.012$, which is $<0.05$, and it is thus concluded that there is a significant relationship between financial support given by the private sector and SMME success as used in this model.

These results are consistent with studies of Chimucheka (2012), Fatoki (2012a), Kamange et al. (2014), Machirori (2012), Mahembe (2012), Mohammed and Obeleagu-Nzelibe (2014), Moorth et al. (2012:227), Mqaba (2015) and Sehhat and Fooman (2014), who also concluded that there is a significant relationship between financial support and business success, although none of these researchers distinguished between the public- and private-sector support, a facet that is a focus of this current study.

\section{Hypothesis 1: Testing for public-sector financial support}

$\mathbf{H}_{01 \mathbf{a}}$ : There is no significant relationship between financial support given by the public sector and SMME success.

$\mathbf{H}_{1 \mathrm{a}}$ : There is a significant relationship between financial support given by the public sector and SMME success.

The statistical tests that were used to test the hypothesis included correlation and multiple regression analyses, and the results obtained are presented in Tables 4 and 5 .

The results from the correlation analyses are summarised in Table 4, which shows the relationship between the predictors of financial support given by the public sector and SMME success. The results suggest that SMME success is positively significantly correlated with only start-up grants $(0.766)$ as a 
predictor of financial support given by the public sector, indicating that start-up as a financial support contributes largely to the success of SMMEs. Raw materials grant $(-0.546)$, infrastructure grants $(-0.641)$ and marketing support grants $(-0.646)$ are significantly negatively correlated, and technology grants $(-0.546)$ are negatively correlated but not significant, indicating that they do not apparently contribute to the SMME success. Table 5 summarises the results of the multiple regression analysis.

The results from the multiple regression model (Table 5) with the five predictors (two predictors - provision of secured funding and provision of non-secured funding - were removed because of collinearity) produced $R^{2}=0.231$, $F_{\text {dist }}=2.260, p=0.048$ (which is $<0.05$ ). The value of $R$-squared indicates $23.1 \%$ variation of SMME success and this can be explained by the financial support predictors.

However, the results from the coefficients of the multiple regression model indicate that a unit increase in SMME success corresponds to a -0.167 significant decrease in raw material financial support grants, -0.021 significant decrease in infrastructure grants, -0.184 decrease in start-up grants and -0.105 decrease in technology grants, and 0.120 increase in marketing support grants weight.

Therefore, the null hypothesis is not accepted as $p=0.048$, which is $<0.05$, and it is concluded that there is a significant relationship between financial support given by the public sector and SMME success as used in this model. These results are consistent with studies of Chimucheka (2012), Fatoki (2012a), Kamange et al. (2014), Machirori (2012), Mahembe (2012), Mohammed and Obeleagu-Nzelibe (2014), Moorth et al. (2012; 227), Mqaba (2015) and Sehhat and Fooman (2014), who also concluded that there is a significant relationship between financial support and business success, although they did not focus on both the private and public sectors:

$\mathbf{H}_{03 \mathrm{a}}$ : There is no concurrence in business interventions delivered by public sector and SMME needs.

$\mathbf{H}_{3 \mathrm{a}}$ : There is a concurrence in business interventions delivered by public sector and SMMEs needs.

$\mathbf{H}_{03 \mathrm{~b}}$ : There is no concurrence in business interventions delivered by the private sector and SMME needs.

$\mathbf{H}_{3 \mathrm{~b}}$ : There is a concurrence in business interventions delivered by the private sector institutions and SMME needs.

To attain this research objective, correlation and multiple regression analyses were conducted and the results showed the concurrence in business interventions delivered by the private- and public-sector institutions and SMMEs needs. Therefore, the results from the multiple regressions led to the conclusion that there is a concurrence in business interventions delivered by the private- and public-sector institutions and SMME needs used in the model. These results are consistent with that of Dalberg (2011) and Mashombo (2014) who indicated that some of the support programmes aimed at the development of SMMEs are relevant to their needs and are yielding a positive impact on the success of SMMEs:

$\mathbf{H}_{04}$ : There is a gap between SMME expectations and the support provided by both private and public sectors.

$\mathbf{H}_{4}$ : There is no gap between SMME expectations and the support provided by both private and public sectors.

To attain this objective, SMMEs were asked if their expectations were met by both public and private sectors. The results showed that more than $90 \%$ of SMMEs indicated that their expectations were not met. This led to the conclusion that a gap exists between SMME expectations and the support provided by both public and private sectors.

These results are consistent with studies conducted by Bae et al. (2014), Bosire and Nzaramba (2014), Buhler (2010), Dalberg (2011) and Mashombo (2014), who indicated that even though SMME support programmes were available, some of the support programmes aimed at development of SMMEs were not relevant to their needs. Thus, the following key findings are drawn up from the results:

- The majority of SMMEs in the Eastern Cape Province of South Africa are managed by their owners.

- Most of the SMMEs in the Eastern Cape Province of South Africa operate small businesses (according to the National Small Business Act 102 of 1996) and employ between 6 and 50 full-time employees.

- Although the respondents were drawn from a number of sectors of the economy including construction and manufacturing, most of the SMMEs operate in the retail and motor trade repair services and construction sector.

- Sixty-one per cent of entrepreneurs have attended at least high school in their level of education. However, very few have university qualifications (degrees).

- The majority of SMMEs operate in rural and semiurban areas and this is because of the nature of the province.

This study also obtained qualitative data from the respondents through the research instrument, and this was done to obtain narrative and descriptive information that was not captured as part of the quantitative data. For the purpose of this study, only two questions in the research instrument were openended, and the results were analysed through grouping responses into different themes. The results are summarised in Tables 6 and 7.

The results indicate that many of the SMMEs suggested that both public and private sectors should interact more with

\begin{tabular}{ll}
\multicolumn{2}{l}{ TABLE 6: How public and private sectors can improve support. } \\
\hline Percentage (\%) & Suggestion \\
\hline 85 & Be more interactive with small, medium and micro enterprises \\
80 & Provision of affordable finance \\
73 & Be more affordable \\
72 & Be more visible \\
68 & More training sessions \\
57 & $\begin{array}{l}\text { Giving attention to more specialised trainings such as planning } \\
\text { and financial control }\end{array}$ \\
38 & Increasing support services packages \\
\hline
\end{tabular}


TABLE 7: Suggestions for improving small, medium and micro enterprises' success.

\begin{tabular}{ll}
\hline Percentage (\%) & Suggestion \\
\hline 90 & Improving access to finance \\
82 & Access to markets \\
78 & $\begin{array}{l}\text { Understanding of small businesses' needs by private and public } \\
\text { sectors }\end{array}$ \\
73 & Helping to grow the business \\
67 & Improving networking \\
88 & Provision of business-specific support \\
\hline
\end{tabular}

SMMEs. Furthermore, SMMEs indicated that the public and private sectors ought to be more visible and provide affordable finance, and also should provide more attention to specialised and demand-driven training. These suggestions are in line with some of the major issues raised in the literature review on the delivery of support to SMMEs. Table 7 provides suggestions that SMMEs made concerning the improvement of their operational businesses.

The results indicate the main areas that SMMEs mentioned would improve their success. The mostly mentioned suggestions were access to markets, improving access to finance, understanding the needs of SMMEs and helping SMMEs to grow, while the least mentioned suggestions were improving networking. These suggestions are also in line with the discussions of many scholars in the area of SMME support and development, and they are also in concurrence with the overall findings of this study.

\section{Contribution to the body of knowledge}

This study has contributed to the body of knowledge on the success of SMMEs by providing new insights into the factors that affect the success of SMMEs. The findings of this study also contribute to the discourse on entrepreneurial success factors, including the debate on whether entrepreneurs can be made (through financial and non-financial support).

The findings also give an idea that the performance of SMMEs is not dependent on one factor at a particular time, but it is affected by a number of factors including both internal and external resources.

This study supports the notion explained by the RBT. It is important to note that financial support can only be relevant if it is used effectively and efficiently at the right stage of business development.

\section{Recommendations}

Based on the findings of this study, recommendations are suggested to SMMEs, the government and private-sector institutions.

\section{The government}

The South African government should continue creating an enabling environment for entrepreneurship and SMME development as this leads to improved job creation. The government should also provide support to such entrepreneurs. However, this support should not be limited to financial components only through loans but ought to include training and provision of networking opportunities.

Modern governments appreciate the role of SMMEs in the economy because they (SMMEs) help governments to achieve goals related to unemployment, income equality and poverty mitigation. The South African government is adhered to ensure that all forms of SMME support are effective and efficient through monitoring and evaluation.

Governments may also support SMMEs by subsidising them and providing loan guarantees. Another recommendation to governments is to relax business legalities and commercial laws restricting SMMEs. This can be achieved through reduced taxation or zero taxation within the first 3 years of commencement, as most SMMEs fail within this period.

\section{Private sector}

It is suggested that financial institutions and other providers of SMME support in the private sector develop products that can respond to specific needs of SMMEs even though SMMEs are in many cases treated as risk customers. Financial institutions should, however, work together with business associations with which SMMEs are affiliated in order to reduce the risk of non-payment of loans. By excluding the greater part of this group, financial institutions are actually losing the market to informal financial service providers.

There is also a need for synergy between the private sector, institutions of higher learning, consulting companies and the public sector so as to avoid duplication of services and to share responsibilities in areas where each stakeholder has strengths. This will enable effectiveness and the efficient use of resources from both private and public sectors.

\section{Owners and/or managers}

The findings of the study at hand revealed significant implications for the management of SMMEs. The owners and/or managers should clearly understand and adopt the appropriate management functions (planning, organising, staffing, leading and controlling), as detailed in this study. This should be implemented in every department to increase business performance.

Most of the SMMEs are sole trader businesses, and this may be restricting SMME growth as synergy of ideas generally results in increased performance. Small, medium and micro enterprises tend to do their business in isolation. There is a need for synergy among SMME practitioners through merging finances, skills, technical know-how, ideas and other resources. This will provide a much-needed robust resource base, which is critically lacking among SMMEs. In this way, SMMEs can achieve growth, develop and create better 
employment opportunities in their geographical areas and access international markets.

Most of the SMMEs, however, are not locally and internationally competitive. There is a need for SMMEs to adopt market analysis, customer feedback and satisfaction and be agents of change when providing their products and services to the market. Most of the SMMEs are just offering similar products to the market resulting in a cut-throat competition. Hence, the need to practise market analysis through employing competent innovative staff qualified for the task.

\section{Small, medium and micro enterprises sector}

The SMME sector is the backbone of the South African economy. Therefore, it is imperative to find ways to increase the performance of SMMEs in order to attain maximum utility of this sector. The research findings highlighted that the performance of SMMEs was limited because of incompetence and other external variables. Of importance is enabling ways to get successful SMMEs to share their best practices with those SMMEs that are struggling. This will in turn improve the knowledge base on the success rate.

The SMME sector should also participate in the development of SMME policy and programmes to ensure that their needs and expectations are taken into account right from the policy development stage so as to bridge the gap between SMME support expectations and what they are actually receiving.

\section{Conclusion}

This research was able to add insight into the existing body of knowledge concerning SMME success in South Africa. The main findings of the study highlighted that financial support is a determinant of SMME success. These findings are consistent with those suggested by RBT. This theory states that, for a business to enjoy competitive advantage, it is only achievable when the business enjoys or has full control of unique resources that cannot be substituted.

However, there is a general indication of a lack of understanding of the needs of SMMEs by both the private and public sectors, thus leading to a lack of knowledge as to how to support these businesses. Over and above that, there is a lack of integration between providers of support from both the private and public sectors, as most are providing similar services to similar segments of the market. This study therefore highlights that programmes that are developed for SMMEs must be demand driven to avoid a mismatch between SMME expectations and the support provided.

It is recommended that there is a separation of responsibilities between the private and public sectors. This will enable thorough monitoring and evaluation of both streams of support programmes and SMME performance. This will increase confidence in support programmes offered to SMMEs.
Concurrently, this will, in future, allow for thorough research into the characteristics that are unique to the South African SMME support environment. This is vital as the literature on South Africa is currently insufficient, thus creating a dependency on literature from other countries that do not have necessarily the same characteristics as SMMEs in South Africa.

It is critical that SMMEs of South Africa are recognised and given an opportunity to grow into viable businesses through the provision of proper and thorough assistance in order for them to be appropriately trained, mentored and properly assisted with essential resources. This will end the notion of a one-size-fits-all approach because each environment has its own unique set of characteristics.

\section{Acknowledgements Competing interests}

The authors declare that they have no financial or personal relationships that may have inappropriately influenced them in writing this article.

\section{Authors' contribution}

E.C.R. was responsible for the entire project and M.P. was responsible for guiding the research process and conceptual contribution of the project.

\section{References}

Bae, T.J., Qian, S., Miao, C. \& Fiet, J.O., 2014, 'The relationship between entrepreneurship education and entrepreneurial intentions: A meta-analytic review', Entrepreneurship Theory and Practice 38(2), 217-254. https://doi.org/10.1111/etap.12095

Beck, T., 2009, Bank financing for SMEs: Evidence across countries and bank ownership types, European Banking Centre Discussion Paper No. 2009-20, Tilburg University, European Banking Centre, Oxford.

Booyens, I., 2011, 'Are small, medium, and micro-sized enterprises engines of innovation? The reality in South Africa', Science and Public Policy 38(1), 67-78. https://doi.org/10.1093/scipol/38.1.67

Bosire, K.J. \& Nzaramba, K., 2014, 'Entrepreneurship skills development and growth of small and medium enterprises in Rwanda (Case Study: "Caplaki") 2007-2011" International Journal of Information Technology and Business Management 17(1), I2-28.

Buhler, P.M., 2010, 'The growing importance of soft skills in the workplace', Super Vision 62(2), 13-15.

Bryman, A., Bell, E., Hirschohn, P., Dos Santos, A., Du Toit, J., Masenge, A. et al., 2014 Research methodology, business and management contexts, Oxford University Press, Cape Town.

Chiliya, N. \& Roberts-Lombard, M., 2012, 'Impact of level of education and experience on profitability of small grocery shops in South Africa', International Journal of Business Management and Economic Research 3(1), 462-470.

Chimucheka, T., 2012, 'The impact of entrepreneurship education on the performance of small, micro and medium enterprises in the Buffalo City Municipality', Master's dissertation, UFH, South Africa.

Chimucheka, T., 2016, 'The impact of motivational and business orientations of owner-managers on the performance of immigrant-owned SMMEs in South Africa', PhD thesis, UFH, South Africa.

Collett, N., Pandit, N.R. \& Saarikko, J., 2014, 'Success and failure in turnaround attempts. An analysis of SMEs within the Finnish Restructuring of Enterprises Act', Entrepreneurship and Regional Development 26(1-2), 123-141. https://doi.org/ 10.1080/08985626.2013.870236

Dalberg, D., 2011, Report on support to SMEs in developing countries through financial intermediaries, viewed n.d., from http://www.eib.org/attachments/dalberg_smebriefing-paper.pdf

Department of Trade and Industry, 2015, Annual financial review of small business in South Africa, 2014-2015, The DTI, Pretoria, South Africa.

Davis, G.F. \& Cobb, J.A., 2010, 'Resource dependence theory: Past and future', Research in the Sociology of Organizations 28(1), 21-42.

Dumbu, E. \& Chidamoyo, P., 2012, 'Managerial deficiencies in the small and medium enterprises (SMEs) in the craft industry: An empirical evidence of SMEs at Great Zimbabwe in Chief Mugabe's area', Journal of Business and Management 4(10), 201. 
Fatoki, O., 2012a, 'An investigation into financial management practices of new microenterprises in South Africa', Journal of Social Sciences 33(2), 179-188. https://doi. org/10.1080/09718923.2012.11893097

Fatoki, O., 2012b, 'The impact of entrepreneurial orientation on access to debt finance and performance of small and medium enterprises in South Africa', Journal of Social Sciences 32(2), 121-131. https://doi.org/10.1080/09718923.201 2.11893058

Fatoki, O.O., 2011, 'The impact of human, social and financial capital on the performance of small and medium-sized enterprises (SMEs) in South Africa, Journal of Social Science 29(3), 193-204. https://doi.org/10.1080/09718923.2011 .11892970

FinMark, 2010, FinScope South Africa Small Business Survey 2010, FinMark Trust viewed 05 June 2016, from http://www.finmarktrust.org.za/pages/Focus-Areas/ Small,-Micro-and-Medium-Enterprises

GEM, 2015, Global Entrepreneurship Monitor, GEM, viewed 30 September 2015, from http://www.gemconsortium.org

Geoffrey, J. \& Christos, P., 2015, 'Entrepreneurial imagination and a demand and supply-side perspective on the MNE and cross-border organization', Journal
of International Management 21,309-325. https://doi.org/10.1016/j.intman. of International
2015.07.003

Gray, D.E., Saunders, M.N. \& Goregaokar, H., 2012, Success in challenging times: Key lessons for UK SMEs, Kingston Smith LLP, London.

Gumbo, A., 2015, The impact of firm characteristics on access to debt and venture capital by SMMEs in the construction industry in King Williams town and Nelson Mandela Metropolitan, South Africa, Master's dissertation, UFH, South Africa.

Kim, J., 2011, 'The effects of workplace financial education on personal finances and work outcomes', unpublished PhD thesis, Virginia Polytechnic Institute and State University, Blacksburg.

Kamange, M.S., Njeru, A. \& Tirimba, O.I., 2014, 'Factors affecting the performance of small and micro enterprises in Limuru Town Market of Kiambu County, Kenya', International Journal of Scientific and Research Publications 4(12), 1-20.

Krajcovicova, K., 2012, Typical managerial competencies of successful managers in enterprises, Milos Cambal, Bratislava, Slovakia.

Lampadarios, E., 2015, 'Critical success factors (CSFs) for small medium enterprises (SMEs): An empirical study in the UK Chemical Distribution Industry', PhD thesis, LBU, Leeds.

Machirori, T. \& Fatoki, O., 2013, 'The impact of firm and entrepreneur's characteristics on networking by SMEs in South Africa', Journal of Economics 4(2), 113-120. https://doi.org/10.1080/09765239.2013.11884971

Machirori, T.L., 2012, 'The impact of networking on access to finance and performance of SMEs in the Buffalo City Municipality, Eastern Cape, South Africa', McComm thesis, UFH, South Africa.

Madya, B., 2015, 'The impact of managerial competencies on the performance of SMEs in the Buffalo City Municipality, South Africa', Master's dissertation, UFH South Africa.

Mahembe, E., 2012, Literature review on small and medium enterprises' access to credit and support in South Africa, South African Final Report NCR 2011, viewed
n.d., from www.ncr.org.za/.../Literature $\% 20$ Review $\% 20$ on $\% 20$ SME $\% 20$ Access $\%$ n.d., from www.ncr.org.za/...
20to\%20Credit and support

Mapfumo, W., 2015, 'The use financial bootstrapping methods among small, medium and micro enterprises in the retail sector of the Buffalo City Municipality South Africa', Master's dissertation, UFH, South Africa.
Maree, K. \& Pietersen, J., 2014, 'The quantitative research process', in K. Maree (ed.), First steps in research, pp. 1-15, Van Schaik Publishers, Pietermaritzburg, SA. Mashombo, W., 2014, 'Factors affecting the delivery of business development services
to agribusiness based micro and small enterprises in Kenya: A case study of Technoserve Kenya', PhD thesis, USIUA.

Mohammed, U.D. \& Obeleagu-Nzelibe, C.G., 2014, 'Entrepreneurial skills and profitability of small and medium enterprises (SMEs): Resource acquisition strategies for new ventures in Nigeria', in 25th International Business Research Conference, Taj Hotel, Cape Town, South Africa, January 13-14, 2014, pp. 1-6.

Moorth, K.M., Tan, A., Choo, C., Wei, C.S., Ping, J.T.Y. \& Leong, T.K., 2012, 'A study on factors affecting the performance of SMEs in Malaysia', International Journal of Academic Research in Business and Social Sciences 2(4), 224-239.

Mqaba, V., 2015, 'The impact of government support on the growth and performance of cooperatives in the Eastern Cape province of South Africa', Master's dissertation, UFH, South Africa.

National Planning Commission, 2011, National development plan 2030, Pretoria. viewed n.d., from https://nationalgovernment.co.za/units/view/35/departmentnational-treasury

National Treasury, 2015, Response to the OECD's 2015 economic report, Pretoria, viewed n.d., from https://nationalgovernment.co.za/units/view/27/departmentnational-treasury

Ngwenya, F., 2012, 'The small and medium-sized enterprises as a vehicle for employment creation in South Africa', in Proceedings of the Clute Institute International Conference, Bangkok, Thailand, March 12-14, 2012, pp. 23-35.

Nkonge, B.K., 2013, 'Challenges faced by small and medium enterprise suppliers when bidding for tenders. A case of Thika District', International Journal of Academic Research in Business and Social Sciences 3(12), 194. https://doi.org/10.6007/ IJARBSS/v3-i12/426

Pergelova, A. \& Angulo-Ruiz, F., 2014, 'The impact of government financial support on the performance of new firms: The role of competitive advantage as an intermediate outcome', Entrepreneurship \& Regional Development 26(9-10) 663-705. https://doi.org/10.1080/08985626.2014.980757

Quinlan, H., 2011, 'The major difficulties and countermeasures of current university graduates' entrepreneurship in China', Journal of Chinese Entrepreneurship 3(3), graduates' entrepreneurship in China', Journal of Chines
228-239. https://doi.org/10.1108/17561391111167000

Sarakunze, A., 2015, 'The effectiveness of business incubators in enhancing survival, growth and performance of SMMEs, South Africa', Master's dissertation, UFH, South Africa.

Sehhat, S. \& Fooman, F.G., 2014, 'The impact of entrepreneurs' knowledge dimensions on SME performance: A study of SMEs in Iran', Management and Administrative Sciences Review 3(3), 389-401.

SME South Africa, 2015, Budget 2015 and SMEs, SME South Africa, viewed 12 September 2015, from http://www.smesouthafrica.co.za/Budget-2015-and-SMEs:15

Statistics South Africa, 2015, Quarter 2. Quarterly Labour Force Survey, Pretoria, viewed n.d., from Http://Www.Statssa.Gov.Za/Default.Asp

Thomola, S.J., Rankhumise, E.M. \& Van Niekerk, B.J., 2010, 'Perceptions of small, medium, micro enterprise entrepreneur regarding factors contributing to failure: A case of Tshwane Metropolitan Municipality', in Proceedings of the African International Business and Management Conference (ALBUMA), University of International Business and Management

Zikmund, W.G. \& Babin, T.K., 2010, Business research methods, Cengage Learning, South-West, Mason, Ohio. 